\title{
Asian snake farms: conservation curse or sustainable enterprise?
}

\author{
Patrick W. Aust, Ngo Van Tri, Daniel J.D. Natusch andGraham J. Alexander
}

\begin{abstract}
Snake farming in Asia has increased over the past decade, and conservationists have expressed concerns that farms may foster overexploitation of wild populations and create legal conduits for illegally harvested wild individuals. We conducted face-to-face interviews with snake farmers in Viet Nam and China, with the aim of describing the basic models under which snakes are farmed for meat. We synthesized this information to assess the feasibility of farming snakes for human consumption, drawing conclusions about the impact of this industry on the conservation of wild snake populations. The most commonly farmed snakes include the monocled cobra Naja kaouthia, the Chinese cobra Naja atra, the oriental rat snake Ptyas mucosus and the king cobra Ophiophagus hannah. These species have life histories that are compatible with the demands of intensive livestock production, including early maturity, rapid growth rates, high reproductive output, efficient food assimilation rates and undemanding space requirements. Snake farmers appear to be capitalizing on the unique energy-efficiency of snakes to produce meat for human consumption. We conclude that the ease and profitability of farming snakes in China and Viet Nam make farming a viable substitute for harvesting wild snakes, with apparently minimal threat to wild populations. Snake farming offers a range of novel agricultural opportunities and has the potential to play a pivotal role in sustainable development.
\end{abstract}

Keywords Asian snake trade, conservation, snake farms, sustainable utilization, wildlife farming

The supplementary material for this article can be found at http://dx.doi.org/10.1017/So03060531600034X.

\section{Introduction}

nakes have been prized in Asia for centuries $\checkmark$ (Dharmananda, 1997; Pipeng et al., 2013). Valued for their meat, skin and medicinal worth, traditionally they

Patrick W. Aust (Corresponding author) and Graham J. Alexander School of Animal, Plant and Environmental Sciences, University of the Witwatersrand, Johannesburg, South Africa. E-mail patwaust@gmail.com

NGO VAN Tri National Key Laboratory, Institute of Tropical Biology, Vietnamese Academy of Sciences and Technology, Ho Chi Minh, Viet Nam

Daniel J.D. Natusch School of Life and Environmental Sciences, University of Sydney, NSW 2006, Australia

Received 1 December 2015. Revision requested 29 February 2016.

Accepted 24 March 2016. First published online 1 July 2016. were harvested from the wild and traded on a localized and sustainable scale (Pipeng et al., 2013). However, since the 199os the demand for snakes and snake products has increased, driven primarily by the growth of Asia's wealthy middle class and increasing demand for luxury goods (Zhou \& Jiang, 2004; Auliya, 2010; Nijman, 2010; Jiang et al., 2013; Cao et al., 2014). By the beginning of the 21st century demand for snake products had begun to outstrip supply, and within a few years the stage was set for uncontrolled international trade, overexploitation of wild populations and escalating risks of a multi-species extinction event (Zhou \& Jiang, 2004, 2005; Pipeng et al., 2013).

Concerns regarding the increasing demand for snake products have persisted over the last decade, during which time the Asian snake trade has become characterized by two key phenomena: (1) the work of the international conservation community to reverse the plight of threatened snake species (e.g. Auliya, 2010; CITES, 2010; Kasterine et al., 2012; Jiang et al., 2013), and (2) the evolution of closed-cycle snake farming systems operated by small-scale farmers responding to market forces (Pipeng et al., 2013; Natusch \& Lyons, 2014). Defined as the production of snakes within a controlled environment without the introduction of specimens from the wild (Natusch \& Lyons, 2014), closed-cycle snake farming is a relatively new industry and little is known about its role in sustainable development. A fundamental lack of baseline information, coupled with a paucity of comparative production models in other parts of the world, has fuelled concerns that snake farms may exacerbate the overexploitation of wild populations and act as a conduit for wild-caught specimens entering the trade illegally (Lyons \& Natusch, 2011; Kasterine et al., 2012; Pipeng et al., 2013).

CITES is responsible for regulating international trade for the majority of snake species that are traded in large numbers (CITES, 2010). In China and Viet Nam at least six CITES-listed snake species are commercially farmed on government-registered farms. Unregistered snake farms also exist, and a number of non-CITES species are also farmed for commercial purposes; however, the scale of these activities is negligible compared to the legal production of CITES-listed species. China and Viet Nam are considered to be the largest and most important producers of, and markets for, snake meat. Calculating the total size of the industry is difficult, although a conservative estimate for China and Viet Nam suggests there are at least 4,00o closedcycle farms producing several million snakes of at least 15 taxa (CITES Management Authority, Viet Nam and Guangxi Forestry Administration, unpubl. data). 
In 2011 the CITES Secretariat convened a technical workshop to consider the conservation priorities and management and enforcement needs of the Asian snake trade. The results were presented at the 16th Meeting of the Conference of Parties to CITES in March 2013, whereupon the CITES Secretariat was instructed to carry out a series of tasks to ensure the overall sustainability, legality and traceability of the trade in CITES-listed snakes. Since that meeting much attention has been focused on the closed-cycle production of large pythons for their skins, and the role of snakes in the luxury leather industry (Kasterine et al., 2012; Natusch \& Lyons, 2014). However, a number of snake farms in Asia are now producing CITES-listed snakes specifically for human consumption, and the demand for snake meat is increasing.

To address the lack of knowledge about closed-cycle snake farming, we visited snake farms in China and Viet Nam as part of a CITES initiative to better understand production systems for snakes farmed primarily for their meat. We aimed to address three questions regarding the conservation implications of snake farming: (1) What are the basic conditions under which snakes are farmed? (2) Is snake farming biologically and ecologically feasible? (3) Are snake farms a sustainable option for meeting all current and future demands for snake meat?

\section{Methods}

During September 2014-January 2015 we conducted face-to-face interviews with managers of 39 independent snake farms. We used a targeted sampling strategy and a semi-structured approach based on a standard series of questions (Supplementary Material 1), with ethical approval from the University of the Witwatersrand, South Africa (Human Non-medical Ethics clearance certificate H14/11/46). We informed all potential interviewees about the aims of the survey, and conducted interviews only with participants who had given their informed consent. We conducted 30 interviews in the Vietnamese provinces of $\mathrm{Ca} \mathrm{Mau}$, Ho Chi Minh City, Tay Ninh, Vinh Phuc and Phu Tho, and nine in the Chinese province of Guangxi. In Viet Nam we surveyed a broad spectrum of licensed snake farms, whereas in China our selection was skewed towards larger commercial farms in an effort to gain a better understanding of the more technologically advanced sector of the industry that has developed there. Nonetheless, we assume a random and representative sample of farms in both China and Viet Nam.

Our survey team consisted of a principal investigator from the University of Witwatersrand, South Africa, one or more government officials, a CITES Management Authority representative, a biologist or herpetologist from a relevant in-country institution, and an interpreter. The interview process was rarely private, and interviews were often carried out in the presence of interested onlookers. Each interview lasted c. 45 minutes. Questions were designed to give an overview of the key biological (e.g. growth, survival and reproduction) and economic parameters (e.g. food, environment and management systems) that defined and determined farm inputs and outputs. Farmers often kept multiple species within a single facility, but usually under separate management regimes. For the analysis, sample size $(n)$ represents the number of responses to each question. Not all farmers answered all questions, and species-specific data were pooled for more general analysis; thus sample size often varied according to question. Pythons were excluded from the analysis because they are farmed primarily for their skins rather than their meat.

\section{Results}

Species Excluding pythons, the four most commonly farmed snakes were the monocled cobra Naja kaouthia, the Chinese cobra Naja atra, the oriental rat snake Ptyas mucosus and the king cobra Ophiophagus hannah. In total we surveyed 25 cobra, 30 oriental rat snake and four king cobra management regimes. We treated $N$. atra and $N$. kaouthia as a single species because of the difficulties in differentiating the two species during fieldwork (probably as a result of hybridization). These study species are farmed primarily for their meat and are all listed in CITES Appendix II (CITES, 2016). Naja atra and O. hannah are also categorized as Vulnerable on the IUCN Red List (Stuart et al., 2012b; Ji \& Li, 2014).

Farm characteristics Snake farms in both China and Viet Nam are variable in terms of scale, ranging from smallholder suburban plots raising a few hundred snakes as a supplementary livelihood activity, to large-scale farms breeding and rearing tens of thousands of snakes as their primary business. Despite substantial variation among individual farms, similar species were farmed at both Chinese and Vietnamese snake farms. We therefore pooled farms from the two countries for our descriptive analyses. Most of the farms surveyed were small, independent operations that bred, raised and sold their own stock. Fifty percent of farms (19 of 39) were $<1,000 \mathrm{~m}^{2}$ $\left(\right.$ mean $=293 \pm$ SD $243 \mathrm{~m}^{2}$ ). Most farms kept more than one species (mean $=2.2 \pm \mathrm{SD} 1.32$ species). Snake enclosure types varied between farms, species and age groups, from small, single-snake cages to large outdoor pits containing many snakes. The more advanced farms (11 of 39) used purpose-built rooms in which several hundred individual snakes were housed within vertical towers of stacked wooden pallets. Stocking rates for adult snakes ranged 
TABLE 1 Key life history and production attributes of the king cobra Ophiophagus hannah, the Chinese cobra Naja atra, the monocled cobra Naja kaouthia and the oriental rat snake Ptyas mucosus, which are farmed for their meat in China and Viet Nam.

\begin{tabular}{|c|c|c|c|c|c|c|}
\hline \multirow[b]{2}{*}{ Attribute } & \multicolumn{2}{|l|}{ Ophiophagus hannah } & \multicolumn{2}{|c|}{ Naja atra \& N. kaouthia } & \multicolumn{2}{|l|}{ Ptyas mucosus } \\
\hline & No. of responses $(\mathrm{n})$ & Mean \pm SD & No. of responses (n) & Mean \pm SD & No. of responses (n) & Mean \pm SD \\
\hline $\begin{array}{l}\text { No. of breeding } \\
\text { females to } 1 \text { male }\end{array}$ & 3 & $0.9 \pm 0.8$ & 15 & $1.5 \pm 0.7$ & 16 & $2.8 \pm 2.3$ \\
\hline Clutch size & 10 & $27 \pm 6.1$ & 21 & $23 \pm 6.7$ & 33 & $15 \pm 2.8$ \\
\hline Incubation failure rate & 3 & $29 \pm 20 \%$ & 8 & $14 \pm 10 \%$ & 14 & $17 \pm 17 \%$ \\
\hline Hatchling mortality rate & 3 & $37 \pm 5 \%$ & 14 & $12 \pm 10 \%$ & 18 & $21 \pm 15 \%$ \\
\hline Age at maturity (years) & 3 & $2.1 \pm 0.2$ & 15 & $1.8 \pm 0.6$ & 17 & $0.9 \pm 2.2$ \\
\hline Mass at maturity $(\mathrm{kg})$ & 2 & $2.5 \pm 0.5$ & 13 & $1.6 \pm 0.3$ & 14 & $1.3 \pm 0.2$ \\
\hline Age at harvest (years) & 3 & $5 \pm 2$ & 14 & $2.5 \pm 1.3$ & 11 & $1.5 \pm 0.7$ \\
\hline Mass at harvest $(\mathrm{kg})$ & 3 & $2.5 \pm 0.1$ & 12 & $2 \pm 0.2$ & 12 & $1.6 \pm 0.3$ \\
\hline Price per kg (USD) & 3 & $81 \pm 18$ & 14 & $31 \pm 6.1$ & 11 & $28 \pm 8$ \\
\hline Feed conversion ratio $(\mathrm{kg})$ & 3 & $5 \pm 0.8$ & 12 & $5.6 \pm 0.6$ & 14 & $6 \pm 1.2$ \\
\hline
\end{tabular}

both within and between farms, from $6.52 \mathrm{~kg} \mathrm{~m}^{-2}$ in single-snake cages to $63 \mathrm{~kg} \mathrm{~m}^{-3}$ in the communal tower block arrays. Forty-one percent of farms (15 of 37 ) provided supplementary heating for snakes through the use of electric heating elements or piped hot water, and four of the large commercial farms provided facilities for snakes to access natural sunlight. The use of various forms of insulation was common. Enclosures were cleaned by hand on average once per week. Only two farms used water to clean enclosures. The standard diet for all species comprised a variety of small vertebrates, fed whole, chopped into pieces or reconstituted into pellets or sausages. With the exception of king cobras, which showed a strong preference for snake meat, virtually all farmers reported generalist dietary tendencies for all species and age groups. We divided primary feed inputs into three categories: wild-harvested natural food (e.g. amphibians and rodents), waste protein from other industries (e.g. poultry and pork) and formulated diets (reconstituted waste protein). Waste poultry was present in $53 \%$ of diets and wild harvested food was present in $46 \%$ of diets $(n=80)$. No live prey was provided; meat was provided either fresh or thawed from frozen. Adult snakes received food weighing a mean of $12 \pm \mathrm{SD} 0.07 \%$ of their body weight $(n=24)$ on average once every $3.3 \pm$ SD 1.5 days $(n=49)$, whereas juveniles were offered food more often (in some cases daily). Breeding adults were fed less and/or less often than non-breeding adults, and less in winter than in summer. All farms provided clean drinking water on a regular basis.

Snake biometrics Life-history attributes important for production of the four snake taxa are summarized in Table 1 and Fig. 1. All farmers had a good understanding of food conversion metrics, as these were used as a means of estimating revenue. On average $5.75 \mathrm{~kg}$ of feed was used to produce $1 \pm$ SD $1.4 \mathrm{~kg}$ of live snake $(\mathrm{n}=39)$. Assuming a

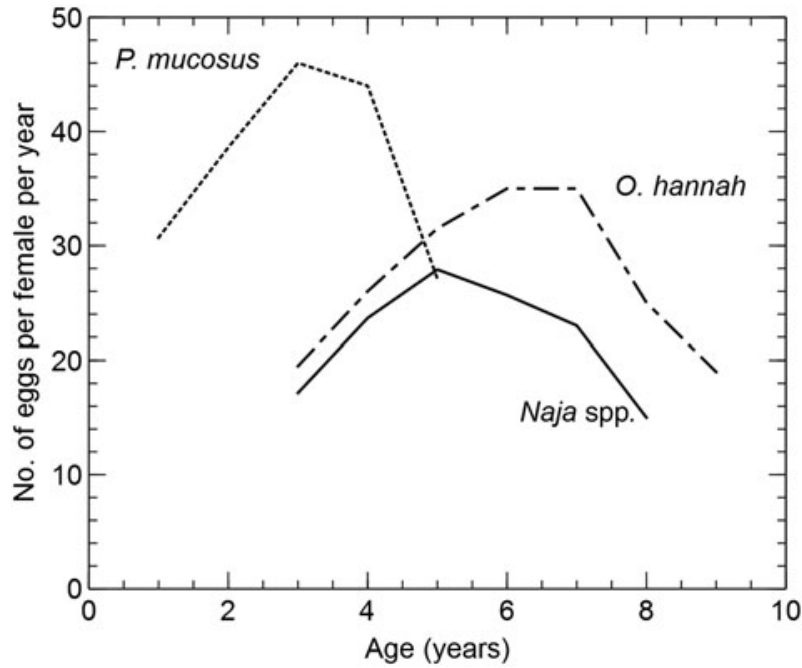

FIG. 1 Comparative reproductive output (no. of eggs) of the king cobra Ophiophagus hannah, the Chinese and monocled cobras Naja spp. and the oriental rat snake Ptyas mucosus, farmed in China and Viet Nam. Year 1 represents the hatch date for all species. Rat snake totals are the sum of up to three clutches per year, whereas the other species only have one clutch per year. Trend line endpoints are a function of harvest and do not necessarily represent senescence.

diet of fresh, whole vertebrate prey with a dry mass of c. $30 \%$ (Dierenfeld et al., 2002), this translates to an equivalent dry food conversion ratio of c. 1.72. Both Chinese and Vietnamese farmers selected snakes with desirable traits (e.g. rapid growth rates and aggressive feeding responses) for breeding purposes. Snakes were sold at a mean mass of $2 \pm$ SD $1.1 \mathrm{~kg}(\mathrm{n}=46)$ and we found no significant difference between the mean mass of individuals at sexual maturity and at sale size (two-sample $t$ test, $t(62)=1.85, \mathrm{P}=0.07$ ). The mean price for a whole live snake was USD $31 \pm$ SD $15.6 \mathrm{~kg}^{-1}(\mathrm{n}=49)$. There was no significant difference between the price of rat snakes and cobras (two-sample $t$ test, $t(35)=0.91, \mathrm{P}=0.4$ ) but the 
TABLE 2 A comparison of the size (no. of snakes) and annual net profit of snake farms in Viet Nam and China.

\begin{tabular}{lcc}
\hline & Viet Nam & China \\
\hline Mean no. of adult snakes per farm (range) & $550 \pm$ SD 527 (30-2,100) & $27,288 \pm$ SD 42,065 (400-130,000) \\
Mean annual net profit per farm (range), USD & $12,476 \pm$ SD 13,714 (1,428-47,619) & $350,716 \pm$ SD 619,403 (7,392-1,968,000) \\
\hline
\end{tabular}

value of king cobras was greater than that of other species (mean $=$ USD $81 \pm$ SD 18). Estimates of the relative value of the snake farming industry in China and Viet Nam in terms of farm size and economic output are in Table 2.

Resilience of snake farming Seventy-four percent of 38 farmers varied their management regime according to prevailing environmental or economic conditions. This included suspending feed inputs in response to fluctuations in feed prices or seasonal availability. Sixteen farmers $(41 \%)$ allowed their snakes to brumate for a mean of $4 \pm$ SD 1.6 months $(n=39)$, during which time management inputs were significantly reduced. The mean estimate of how long their stock could survive without feeding, and without lasting consequences to production output (e.g. in the event of an environmental catastrophe) was $4.3 \pm$ SD 3.7 months $(n=34)$.

\section{Discussion}

Closed-cycle snake farming has emerged as a viable livestock industry supplying snakes to the international trade. In Viet Nam and China the four main species farmed for their meat are P. mucosus, N. atra, N. kaouthia and O. hannah. A variety of production models are used but all species have broadly similar life histories and are compatible with the biological prerequisites for commercial production. Snake farming is a profitable livelihood activity for rural communities, and in some cases may offer novel opportunities because primary production parameters are resource efficient and resistant to environmental perturbations.

Although studies have suggested that wildlife farming enterprises may have a negative impact on wild populations (e.g. Drury, 2009; Brooks et al., 2010; Lyons \& Natusch, 2011; Cunningham et al., 2016), our study supports the hypothesis that in the right context wildlife farming can mitigate the drivers of uncontrolled wild harvests, and in some cases incentivize conservation action (e.g. Gordon \& Ayiemba, 2003; Hardouin et al., 2003; MacGregor, 2006; Nogueira \& Nogueira-Filho, 2011; Natusch \& Lyons, 2014). Given the ease and economic viability of producing snakes within closed-cycle systems, it is likely that this industry poses minimal conservation threat to wild snake populations.

There were three primary limitations to our study. Firstly, our findings relied on information supplied by farmers themselves, and we typically conducted interviews in the presence of an audience (e.g. family members, neighbours), which may have compromised objectivity (e.g. legal issues, social pressures). Secondly, the farm selection process was potentially biased towards more successful farms, which may have positively skewed our conclusions. A third limitation applies mainly to the king cobra data, where a small sample size and problems experienced during the first day of fieldwork (which coincided with two of the four king cobra interviews) may have compromised the data. Nevertheless, the findings demonstrate the parameters of a viable industry and are broadly corroborated by existing literature (e.g. Haitao et al., 2008; Cunningham et al., 2016).

\section{Biological feasibility}

Conventional logic states that energy efficiency, and therefore production efficiency, decreases towards the apex of the trophic pyramid (e.g. Odum et al., 1971). Theoretically, snakes are unsuitable for commercial meat production because they are predators and obligate carnivores. However, the ectothermic metabolic response of reptiles results in a more efficient conversion of biomass compared to mammals and birds (up to 90\% more efficient; Pough, 1980). This feat is achieved through several unique adaptations, including efficient digestive physiologies (Bedford \& Christian, 2000; Secor, 2003), judicious activity patterns (e.g. Slip \& Shine, 1988), the ability to regulate metabolic rate according to resource availability (Secor, 2001) and the ability to harness solar energy to negate the cost of metabolic thermoregulation (Seigel et al., 1993). Our findings suggest that snakes fed on a rudimentary diet may have dry feed conversion ratios comparable to poultry fed on scientifically formulated diets (Steinfeld et al., 2006).

The species of snakes included in our study grow rapidly, mature early and have a high reproductive output. These traits are generally more accentuated in farmed animals compared to wild conspecifics (Fig. 1; Stuart et al., 2012a,b; Ji \& Li, 2014). The nutritional composition of the diets of farmed snakes was broadly similar to natural diets (Dierenfeld et al., 2002; Whitaker et al., 2004). In terms of behaviour, several species of snakes tend to aggregate (Gregory, 2004; Reed \& Rodda, 2009) and appear to be relatively tolerant of high stocking densities. Snakes are also adapted to exploit a three-dimensional spatial landscape, displaying dual terrestrial and arboreal tendencies (e.g. Alexander \& Marais, 2007). Thus stocking rates may be nearly double the $33 \mathrm{~kg} \mathrm{~m}^{-2}$ recommended for meat 
chickens in the UK (DEFRA, 2012). In terms of biology, snake farming could potentially offer a cheaper, more humane and more resource-efficient solution to food security. Snakes are relatively cheap and easy to produce in a captive setting, compared to the effort required to find and capture wild snakes on a commercial scale, and therefore snake farming could reduce illegal wild harvests.

\section{Ecological sustainability}

Direct measures of ecological sustainability were limited, and thus we relied on a number of assumptions and inferences to facilitate objective interpretation. The landscape in much of Viet Nam is dominated by a patchwork mosaic of small-scale agriculture and wetlands (Dang et al., 2007), and farming methods remain largely traditional (e.g. harvesting is by hand). These mixed agroecosystems support a rich diversity of anthropophilic species (Brown et al., 2006; Halwart, 2006), many of which are abundant and resilient to seasonal exploitation. Examples of such species include amphibians and commensal rodents (Lawler, 2001; Gray et al., 2004; Brown et al., 2006), which are important food inputs for the snake farming industry. By placing a value on these species, snake farmers are indirectly creating a financial incentive for preserving holistic environmentfriendly farming practices, particularly where these are threatened by the advance of monocultures. The other important feed input in the snake farming industry comprises by-products from existing food production chains. Snake farms essentially recycle low-value waste protein from the poultry, pork and fish industries and repackage it into a high-value protein suitable for human consumption in the form of snake meat.

Snake farms require relatively minimal freshwater or chemical inputs and produce low levels of biological waste. In terms of ecological imperatives, snake farming is in line with the principles of agroecological land-use practices and conservation agriculture (e.g. Jat et al., 2013; Scialabba et al., 2014), and may be a potential livelihood strategy for communities living within the buffer zones of protected areas (Hardouin et al., 2003).

\section{Social impact}

Snake farming requires minimal land or start-up capital and is an accessible, low input livelihood option for rural and peri-urban small-scale farmers. It is often carried out in parallel with other livelihood activities such as rice farming or paid employment, and in these situations it often represents a windfall income or insurance policy (Nossal et al., in press). The unique physiology of snakes offers vulnerable farmers flexibility in the way they cope with volatile economic and environmental conditions. By means of adaptive metabolic regulation pythons can digest and assimilate large meals relatively quickly and then survive for long periods with no food (Pope, 1961; Secor \& Diamond, 1995, 1998, 2000). Snakes are not only adept at exploiting seasonal gluts, they are also capable of surviving periods of famine (Pope, 1961), and this gives farmers the freedom to synchronize feed inputs with trends in local resources; for example, some farmers rely on amphibians during the monsoon season and rodents during the rice harvest season to provide the bulk of their annual feed inputs. Famine is often associated with increasing variability in climate, and in this context snake farming could be a unique buffer against the impacts of climate change. Snake farming has also proved to be a resilient livelihood activity in the face of increasingly frequent epidemics of $\mathrm{H}_{5} \mathrm{~N}_{1}$-type avian influenza (P. Aust, unpubl. data), as the virus only infects endothermic animals such as pigs and poultry (Peiris et al., 2007).

\section{Welfare issues}

The livestock industry often attracts the attention of animal welfare groups because it advocates the intensive production of higher-order vertebrates. Snakes display markedly inferior cognitive abilities compared to endothermic species such as poultry and pigs (Burghardt, 1988), and although their aggregation behaviour facilitates comparatively high stocking densities, overall the surface area per individual remains relatively high because of their arboreal behaviour; for example, a stocking density of $63 \mathrm{~kg} \mathrm{~m}^{-3}$ actually equates to $6.3 \mathrm{~kg} \mathrm{~m}^{-2}$ after accounting for shelf space, which is well below the recommended stocking density for meat chickens (DEFRA, 2012). Currently, most production parameters fall within the broader standards prescribed by science-based snake husbandry guidelines (e.g. Pough, 1991) but issues such as veterinary care, transport and slaughter could benefit from further animal welfare-focused research and development.

\section{Direct conservation outcomes}

Wildlife farming in South-east Asia is often perceived to have negative impacts on wildlife conservation because it relies on, or at least exacerbates, the overexploitation of wild populations (Drury, 2009; Brooks et al., 2010; Cunningham et al., 2016). However, our findings suggest that closed-cycle snake farming is both possible and profitable, and cheap, high-quality farmed snakes could potentially reduce the demand for wild-caught snakes. Competition from snake farms combined with prohibitive legislation and improved law enforcement has already forced some professional snake hunters to turn to snake farming as an alternative livelihood (P. Aust, unpubl. data). Furthermore, snake farmers appear to place 
significant importance on selective breeding as a means of increasing productivity. The fear of contaminating carefully selected genetics with wild-type genes, in addition to the risks of introducing parasites and infectious diseases, provides at least some motivation for farmers to actively prevent wild snakes from entering the commercial farm environment. Nonetheless, there is little to prevent people from opportunistically capturing wild snakes and selling them into trade (possibly as captive-bred individuals), and we should assume this occurs in some cases. Although such small-scale harvest is unlikely to present problems for species that thrive in anthropogenic environments (Boeadi et al., 1998; Shine et al., 1999; Auliya, 2010), it may create challenges for the conservation of less plastic species, such as the king cobra (Stuart et al., 2012b). A similar harvestrelated question arises over the industry's use of wild animals as a food source for snakes, and whether or not this constitutes a sustainable practice. Further research is needed to clarify the role snake farming plays in the conservation of wild populations and identify strategies whereby snake farming enhances rather than jeopardizes incentives for the conservation of wild snakes.

\section{Conclusion}

The diversity of snake farming models reflects the embryonic and dynamic nature of the snake farming industry, and confirms that closed-cycle production is viable. Initially based on modified traditional livestock farming systems, the industry now appears to be in the process of adopting modern biological and technological know-how to improve the efficiency and profitability of a divergent and formerly poorly known livestock taxon. Our findings indicate that snake farming is a potentially cheap and resource-efficient source of high-quality animal protein. Expansion of the industry within Asia is expected and should be encouraged, with caution, in some contexts, ideally with a more holistic knowledge of the broader environment and incentive structure snake farming may create. In this regard the development process underpinning the industry could benefit from a multidisciplinary research framework focused specifically on exploring the interface between snake biology, agricultural technology and environmental sustainability. In the longer term, snake farming may also have global applications, and there is at least some potential for establishing snake farming as a tool for agricultural development, particularly within regions where historical snake-eating practices have been suppressed by colonial legacies.

\section{Acknowledgements}

Funding for this study was generously provided by the CITES Secretariat, the IUCN SSC Boa and Python
Specialist Group, the Carnegie Corporation of New York (Global Challenge Initiative) and the National Research Foundation of South Africa. We thank the following organizations for their contribution of staff time and institutional support towards fieldwork: The Institute of Tropical Biology, Viet Nam; the CITES Management Authorities of Viet Nam and China; the Forest Protection Departments of Ca Mau, Ho Chi Minh City, Tay Ninh, Vinh Phuc and Phu Tho provinces (Viet Nam); The Endangered Species Scientific Commission Office, Institute of Zoology, Chinese Academy of Sciences; Shenyang Normal University (China); The Endangered Species Import and Export Management Office (China); The Endangered Species Scientific Commission, China CITES Scientific Authority; The Division of Wildlife Conservation, Guangxi Forestry Administration (China); and the Lingshan Forestry Administration, Qinzhou City (China). We are also grateful to the many farmers, farm staff and other industry stakeholders who participated in interviews and took time to answer our questions.

\section{References}

Alexander, G. \& Marais, J. (2007) A Guide to the Reptiles of Southern Africa. Struik Publishers, Cape Town, South Africa. A uliy A, M. (2010) Conservation Status and Impact of Trade on the Oriental Rat Snake Ptyas mucosa in Java, Indonesia. TRAFFIC Southeast Asia, Petaling Jaya, Selangor, Malaysia.

Bedford, G.S. \& Christian, K.A. (2000) Digestive efficiency in some Australian pythons. Copeia, 2000, 829-834.

Boeadi, S., Shine, R., Sugardjito, J., Amir, M. \& Sinaga, M.H. (1998) Biology of the commercially harvested rat snake (Ptyas mucosus) and cobra (Naja sputatrix) in Central Java. Mertensiella, 9, 99-104.

Brooks, E.G., Roberton, S.I. \& Bell, D.J. (2010) The conservation impact of commercial wildlife farming of porcupines in Vietnam. Biological Conservation, 143, 2808-2814.

Brown, P.R., Nguyen, P.T., Singleton, G.R., Ha, P.T., Hoa, P.T., HuE, D.T. et al. (2006) Ecologically based management of rodents in the real world: applied to a mixed agroecosystem in Vietnam. Ecological Applications, 16, 2000-2010.

Burghardt, G.M. (1988) Precocity, play, and the ectothermendotherm transition: profound reorganization or superficial adaptation? In Developmental Psychobiology and Behavioral Ecology (ed. E.M. Blass), pp. 107-148. Plenum Press, New York, USA.

Cao, N.V., Nguyen, T.T., Moore, A., Montoya, A., Redsted Rasmussen, A., Broad, K. et al. (2014) Sea snake harvest in the Gulf of Thailand. Conservation Biology, 28, 1677-1687.

CITES (2010) Snake trade and conservation management. In Fifteenth Meeting of the Conference of the Parties, Doha (Qatar), 13-25 March 2010.

CITES (2016) The CITES Appendices. Http://www.cites.org/eng/app/ index.shtml [accessed 16 May 2016].

Cunningham, A.A., Turvey, S.T., Zhou, F., Meredith, H.M., Wei, G., LiU, X. et al. (2016) Development of the Chinese giant salamander Andrias davidianus farming industry in Shaanxi Province, China: conservation threats and opportunities. Oryx, 50, 265-273. 
Dang, K.N., Le, T.P., Verdegem, M.J.C., Le, T.D., Bosma, R.H. \& LitTLE, D.C. (2007) Integrated freshwater aquaculture, crop and livestock production in the Mekong delta, Vietnam: determinants and the role of the pond. Agricultural Systems, 94, 445-458.

DeFra (Department for Environment, Food \& Rural Affairs) (2012) Broiler Chickens and Breeder Chickens: Welfare Regulations. Https://www.gov.uk/guidance/welfare-for-meatchickens-and-breeding-chickens [accessed 28 May 2015].

Dharmananda, S. (1997) The medicinal use of snakes in China. Http://www.itmonline.org/arts/snakes.htm [accessed January 2015].

Dierenfeld, E.S., Alcorn, H.L. \& Jacobsen, K.L. (2002) Nutrient Composition of Whole Vertebrate Prey (Excluding Fish) Fed in Zoos. U.S. Department of Agriculture, Agricultural Research Service, National Agricultural Library, Animal Welfare Information Center, Beltsville, USA.

DRURY, R. (2009) Reducing urban demand for wild animals in Vietnam: examining the potential of wildlife farming as a conservation tool. Conservation Letters, 2, 263-270.

Gordon, I. \& Ayiemba, W. (2003) Harnessing butterfly biodiversity for improving livelihoods and forest conservation: the Kipepeo Project. The Journal of Environment \& Development, 12, 82-98.

Gray, M.J., SMith, L.M. \& Brenes, R. (2004) Effects of agricultural cultivation on demographics of Southern High Plains amphibians. Conservation Biology, 18, 1368-1377.

Gregory, P.T. (2004) Analysis of patterns of aggregation under cover objects in an assemblage of six species of snakes. Herpetologica, 6o, 178-186.

Haitao, S., Parham, J.F., Zhiyong, F., Meiling, H. \& Feng, Y. (2008) Evidence for the massive scale of turtle farming in China. Oryx, 42, 147-150.

Halwart, M. (2006) Biodiversity and nutrition in rice-based aquatic ecosystems. Journal of Food Composition and Analysis, 19, 747-751.

Hardouin, J., Thys, E., Joiris, V. \& Fielding, D. (2003) Mini-livestock breeding with indigenous species in the tropics. Livestock Research for Rural Development, 15, 5.

Jat, R.A., Sahrawat, K.L. \& Kassam, A.H. (2013) Conservation Agriculture: Global Prospects and Challenges. CABI, Wallingford, UK.

JI, X. \& LI, P. (2014) Naja atra. The IUCN Red List of Threatened Species 2014: e.T192109A2040894. Http://dx.doi.org/10.2305/IUCN. UK.2014-3.RLTS.T192109A2040894.en [accessed 16 May 2016].

Jiang, Z., Zhou, Z., Meng, Z., MenG, X., Li, L., PinG, X. et al. (2013) Domestic and CITES regulations controlling the international snake trade in China. Oryx, 47, 532-534.

Kasterine, A., Arbeid, R., Caillabet, O. \& Natusch, D. (2012) The Trade in South-East Asian Python Skins. International Trade Centre, Geneva, Switzerland.

LAWLER, S.P. (2001) Rice fields as temporary wetlands: a review. Israel Journal of Zoology, 47, 513-528.

Lyons, J.A. \& NATUSCH, D.J.D. (2011) Wildlife laundering through breeding farms: illegal harvest, population declines and a means of regulating the trade of green pythons (Morelia viridis) from Indonesia. Biological Conservation, 144, 3073-3081.

MacGregor, J. (2006) The Call of the Wild: Captive Crocodilian Production and the Shaping of Conservation Incentives. TRAFFIC International, Cambridge, UK.

Natusch, D.J. \& Lyons, J.A. (2014) Assessment of Python Breeding Farms Supplying the International High-end Leather Industry. IUCN, Gland, Switzerland.

Nijman, V. (2010) An overview of international wildlife trade from Southeast Asia. Biodiversity and Conservation, 19, 1101-1114.

Nogueira, S.S.C. \& Nogueira-Filho, S.L.G. (2011) Wildlife farming: an alternative to unsustainable hunting and deforestation in Neotropical forests? Biodiversity and Conservation, 20, $1385-1397$.
Nossal, K., Livingston, D.G., Aust, P., Bozzola, M., Kasterine, A., NGo Viet, C. et al. (in press) The Impact of the Python Skin Trade on Livelihoods in Viet Nam. International Trade Centre, Geneva, Switzerland.

Odum, E.P., Odum, H.T. \& Andrews, J. (1971) Fundamentals of Ecology. Saunders, Philadelphia, USA.

Peiris, J.S., De Jong, M.D. \& Guan, Y. (2007) Avian influenza virus $\left(\mathrm{H}_{5} \mathrm{~N}_{1}\right)$ : a threat to human health. Clinical Microbiology Reviews, 20, 243-267.

Pipeng, L., Weisheng, W. \& Xiaoping, L. (2013) Snake conservation and sustainable utilization in China: history, status and future. Journal of Shenyang Normal University (Natural Science), 31.

Pope, C.H. (1961) The Giant Snakes. Routledge \& Kegan Paul, London, UK.

Pough, F.H. (1980) The advantages of ectothermy for tetrapods. The American Naturalist, 115, 92-112.

Pough, F.H. (1991) Recommendations for the care of amphibians and reptiles in academic institutions. ILAR Journal, 33, S1-S21.

Reed, R.N. \& Rodda, G.H. (2009) Giant Constrictors: Biological and Management Profiles and an Establishment Risk Assessment for Nine Large Species of Pythons, Anacondas, and the Boa Constrictor. U.S. Geological Survey, Reston, USA.

Scialabba, N.E.-H., Pacini, C. \& Moller, S. (2014) Smallholder Ecologies. FAO, Rome, Italy.

SECOR, S.M. (2001) Regulation of digestive performance: a proposed adaptive response. Comparative Biochemistry and Physiology Part A: Molecular and Integrative Physiology, 128, 563-575.

SECOR, S.M. (2003) Gastric function and its contribution to the postprandial metabolic response of the Burmese python Python molurus. Journal of Experimental Biology, 206, 1621-1630.

Secor, S.M. \& Diamond, J. (1995) Adaptive responses to feeding in Burmese pythons: pay before pumping. Journal of Experimental Biology, 198, 1313-1325.

SeCor, S.M. \& Diamond, J. (1998) A vertebrate model of extreme physiological regulation. Nature, 395, 659-662.

SECOR, S.M. \& Diamond, J. (2000) Evolution of regulatory responses to feeding in snakes. Physiological and Biochemical Zoology, 73, 123-141.

Seigel, R.A. \& Collins, J.T. (1993) Snakes: Ecology and Behavior. McGraw-Hill, New York, USA.

Shine, R., Ambariyanto, Harlow, P.S. \& Mumpuni (1999) Reticulated pythons in Sumatra: biology, harvesting and sustainability. Biological Conservation, 87, 349-357.

SLIP, D.J. \& Shine, R. (1988) Habitat use, movements and activity patterns of free-ranging diamond pythons, Morelia spilota spilota (Serpentes, Boidae): a radiotelemetric study. Wildlife Research, 15, $515-531$.

Steinfeld, H., Gerber, P., Wassenaar, T., Castel, V., Rosales, M. \& DE HAAN, C. (2006) Livestock's Long Shadow: Environmental Issues and Options. FAO, Rome, Italy.

Stuart, B., Nguyen, T.Q., Thy, N., Grismer, L., Chan-Ard, T., IsKANDAR, D. et al. (2012a) Python bivittatus. The IUCN Red List of Threatened Species 2012: e.T193451A2237271. Http://dx.doi.org/10. 2305/IUCN.UK.2012-1.RLTS.T193451A2237271.en [accessed 16 May 2016].

Stuart, B., Wogan, G., Grismer, L., Auliya, M., Inger, R.F., Lilley, R. et al. (2012b) Ophiophagus hannah. The IUCN Red List of Threatened Species 2012: e.T177540A1491874. Http://dx.doi.org/10. 2305/IUCN.UK.2012-1.RLTS.T177540A1491874.en [accessed 16 May 2016].

Whitaker, R., Captain, A. \& Ahmed, F. (2004) Snakes of India. Draco Books, India.

ZHOU, Z. \& JIANG, Z. (2004) International trade status and crisis for snake species in China. Conservation Biology, 18, 1386-1394. 
ZHOU, Z. \& JIANG, Z. (2005) Identifying snake species threatened by economic exploitation and international trade in China. Biodiversity and Conservation, 14, 3525-3536.

\section{Biographical sketches}

PATRICK AUST is a conservation biologist with a particular interest in applied herpetology. $\mathrm{He}$ is currently exploring the agricultural potential of reptiles within a sustainable food security context. NGO VAN TRI is a conservation biologist specializing in herpetological taxonomy and wildlife forensics. DANIEL NATUSCH is a biologist working on the ecology, conservation and trade of reptiles in the AsiaPacific region. Graham Alexander has a particular interest in elucidating causality of range limitation in reptiles, and using this information for conservation purposes. He is currently focusing on the importance of snakes as predators in South African ecosystems. 